\title{
Long-term bending properties of cross-laminated timber made from Japanese larch under constant environment
}

\author{
Ryuya Takanashi ${ }^{*} \mathbb{D}$, Yoshinori Ohashi, Wataru Ishihara and Kazushige Matsumoto
}

\begin{abstract}
Cross-laminated timber (CLT) has been used extensively in timber construction. CLT panels are typically used in roofs and floors that carry a continuous load, and it is important to examine the long-term loading capacity of CLT. However, studies that focus on the long-term loading capacity of CLT are limited. To this end, we conducted long-term out-of-plane bending tests on seven-layer CLT made from Japanese larch (Larix kaempferi) under constant environmental conditions, investigated creep performance and duration of load, and experimentally analyzed creep rupture behavior. The mean estimated relative creep after 50 years was 1.49. The sample showed a satisfactory resistance to creep as a building material. The duration of load of most of the specimens in this study was shorter than the conventional value of small clear wood specimens. Specimens had a lower duration of load capacity than solid lumber. According to the results of survival analysis, a loading level of 70\% or more caused the initial failure of specimens. Creep rupture of most of the specimens occurred at less deflection than displacement at failure in the short-term loading test. Additional studies focusing on the effects of finger joints, transverse layers, and width of a specimen on creep rupture behavior are suggested.
\end{abstract}

Keywords: Creep, Creep rupture, Duration of load, Out-of-plane bending, Survival analysis

\section{Introduction}

Wood and wooden materials are important building materials. In recent years, timber construction has gained interest globally for use in many fields, such as residential, office, and school buildings [1]. One reason for this trend is the increased use of cross-laminated timber (CLT) [1]. CLT panels consist of several layers of lumber stacked crosswise and glued together on their wide faces [2]. Owing to this configuration, CLT is formed in a plate-like shape and can carry a load both in-plane and out-of-plane. This enables easy handling in construction and a high level of prefabrication, and thus, CLT construction can be competitive in mid- and high-rise buildings [2].

*Correspondence: takanashi-ryuuya@hro.or.jp

Forest Products Research Institute, Hokkaido Research Organization, 1-10 Nishikagura, Asahikawa 071-0198, Japan
Owing to orthogonal layering, CLT has specific material properties derived from the anisotropy of mechanical characteristics of wood. For out-of-plane bending in CLT, several theories have been published to explain its bending stiffness and strength [2], and experimental studies have been conducted [3]. However, these studies have focused only on short-term loading, but wood and wooden materials can demonstrate other characteristic behaviors under a continuous load due to their viscoelasticity. When a load is maintained, time-dependent deformation occurs, adding to the initial elastic deformation. This deformation increase phenomenon is called creep. Creep is an important factor in determining the load a material can carry, ensuring long-term serviceability. Many studies have investigated the creep behavior of wood and wooden materials [4-12]. In addition, if the stress is sufficiently high, failure will occur under constant load. This failure phenomenon is called creep 
rupture [13]. The duration of load, the time during which a load acts until creep rupture, is an important factor in determining the load that a member can carry, ensuring long-term safety. Several studies have investigated the duration of load of wood and wooden materials $[8,11,14$, 15].

CLT panels that make up roofs and floors carry the mid- and long-term loads such as snow accumulation in some regions and the fixed load weight of a structure. Therefore, it is necessary to understand the long-term loading behavior of CLT. The creep performance and duration of load of CLT have been investigated [9-12], but these studies mainly focused on CLT made from Japanese cedar (Cryptomeria japonica) or kinds of spruce. To the best of our knowledge, there have been no reports that investigated the creep performance and duration of load of CLT made from Japanese larch (Larix kaempferi). Japanese larch is a major planted tree species in the cold climates area of Japan and has a high Young's modulus when used as timber. Therefore, CLT made from Japanese larch is suitable for structural materials, especially horizontal applications such as in floors or roofs. It can be used in various structural designs that require high stiffness of members, such as long floor spans or cantilever designs. Thus, it is important to investigate the creep performance and duration of load of CLT made from Japanese larch to ensure long-term serviceability and safety. In this study, we conducted long-term out-of-plane bending tests on seven-layer CLT made from Japanese larch, investigated creep performance and duration of load, and experimentally analyzed the creep rupture behavior.

\section{Materials and methods Specimens}

CLT specimens contained seven layers with three crosssections and were composed of Japanese larch. Laminae were $105 \mathrm{~mm}$ width and $30 \mathrm{~mm}$ thickness and adhered using an aqueous polymer isocyanate adhesive on the longitudinal connections and lamination. The criteria for stress grading of the laminae for manufacturing CLT panels were $11-13 \mathrm{kN} / \mathrm{mm}^{2}$ in the outmost layers and 6-11 $\mathrm{kN} / \mathrm{mm}^{2}$ in other layers. Eleven CLT panels that have $2700 \mathrm{~mm}$ width and $6000 \mathrm{~mm}$ length (Nos. 1 to 11) were manufactured, and CLT specimens were cut from these panels. The dimensions of the CLT specimens were $300 \mathrm{~mm}$ width, $210 \mathrm{~mm}$ thickness, and $4610 \mathrm{~mm}$ length. The grain direction of the outmost layers was parallel to the long direction of the specimens. Six side-matched specimens were cut from each panel, including one specimen for the short-term loading test, one specimen for the creep test, and four specimens for the creep rupture test (Fig. 1). Therefore, the number of specimens were 11

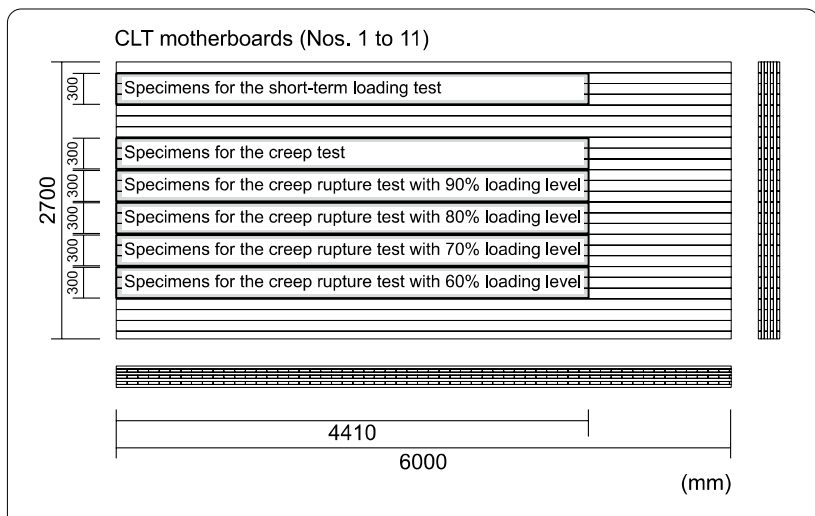

Fig. 1 Cutting pattern of specimens from CLT motherboards

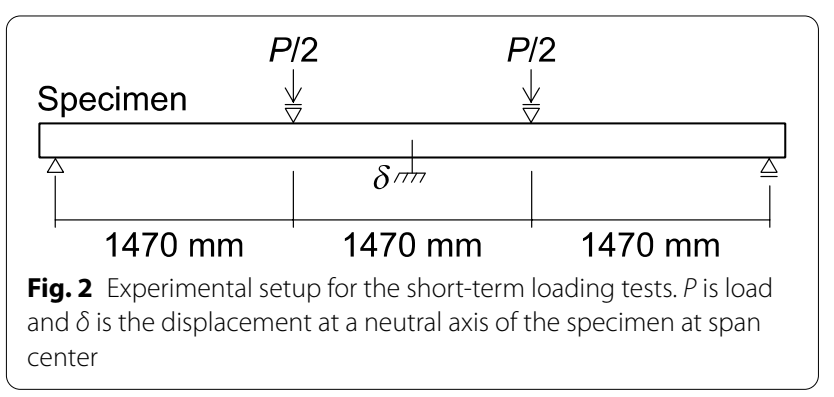

for the short-term loading tests, 11 for the creep test, and 44 for the creep rupture test.

\section{Short-term loading tests}

Figure 2 shows the experimental setup for the short-term loading tests. A four-point bending test was conducted using a testing machine with a maximum loading capacity of $200 \mathrm{kN}$, and the cross-head moving speed was at $10 \mathrm{~mm} / \mathrm{min}$. The loading direction was out-of-plane of CLT. Following the Japanese Agricultural Standard for CLT [16], the support span was 21 times the specimen thickness and the loading points were along the trisected support span. Both the load $(P)$ and displacement at a neutral axis of the specimen at the span center from the ground $(\delta)$ were measured. Then, the bending modulus of elasticity $\left(E_{\mathrm{m}}\right)$ and bending strength $\left(\sigma_{\mathrm{b}}\right)$ were, respectively, calculated as follows:

$$
\begin{aligned}
& E_{\mathrm{m}}=23 \Delta P L^{3} / 108 \Delta \delta b h^{3}, \\
& \sigma_{\mathrm{b}}=P_{\max } L / b h^{2},
\end{aligned}
$$

where $P_{\max }$ is the maximum load, $\Delta P$ is the load increase in an elastic range $\left(0.4 P_{\max }-0.1 P_{\max }\right.$ for this study), $\Delta \delta$ is an increase in $\delta$ with $\Delta P, L$ is the length of the support 
span $(4410 \mathrm{~mm}), b$ is the specimen width $(300 \mathrm{~mm})$, and $h$ is the specimen thickness $(210 \mathrm{~mm})$.

The moisture content of the specimens was measured after the tests using the oven-dried weight of specimen pieces.

\section{Creep tests}

Figure 3 shows the experimental setup for the creep tests. The testing instruments are capable of loading approximately 17 times the suspended weight at the end of the moment arm. The tests were conducted at a constant temperature $\left(20{ }^{\circ} \mathrm{C}\right)$ and relative humidity $(65 \% \mathrm{RH})$ conditions. A four-point bending setup was used, which was equivalent to the short-term loading test. A gradual descent of the weight was used to load the specimens to avoid impact loading. The constant load applied to the specimens was $37 \%$ of the mean of the maximum load observed in the short-term loading test. A loading level of $37 \%$ is derived from the conventional allowable longterm stress in the Japanese building code as follows:

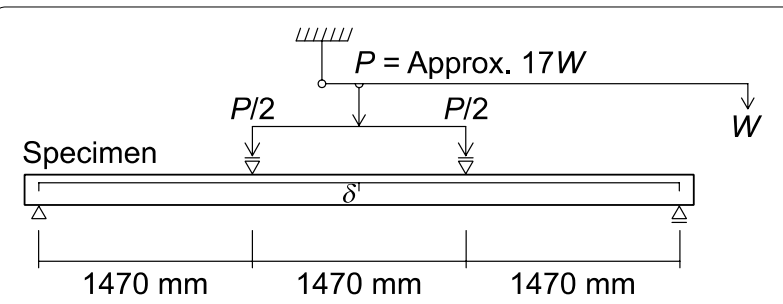

Fig. 3 Experimental setup for creep and creep rupture tests. $P$ is load, $W$ is suspended weight at the end of the moment arm, and $\delta$ is displacement at a neutral axis of the specimen at span center

$$
37 \%=(2 / 3) \times 55 \%,
$$

where $2 / 3$ is the factor of allowable short-term stress and $55 \%$ is the factor of the duration of load.

The deflection was measured at a neutral axis of the specimen at the span center $(\delta)$, with a yoke on one side of the specimen between the support span. The measurement start time was after loading, and the measurement interval was $1 \mathrm{~min}$. The test periods ranged from 48 to 183 days because of interruption of constant environmental conditions and termination of a test.

\section{Creep rupture tests}

Creep rupture tests were conducted using the same testing instruments (Fig. 3) and conditions as those in the creep test. The constant load applied to each of the four side-matched specimens was $60 \%, 70 \%, 80 \%$, and $90 \%$ of the mean of the maximum load observed in the short-term loading test. The deflection was measured at a neutral axis of the specimen at the span center $(\delta)$. The measurement was continued until specimen failure. The duration of load, which is the time to failure, was calculated as the duration between test start time and failure. The moisture content of the specimens was measured after failure using the oven-dry weight of specimen pieces.

\section{Results and discussion}

\section{Short-term loading tests}

Table 1 shows the results for the short-term loading tests, and Fig. 4 shows the load-displacement curves of all specimens. All specimens demonstrated a bending failure, and most were broken at a finger joint or knot in the tensile

Table 1 Results of the short-term loading tests

\begin{tabular}{|c|c|c|c|c|c|c|c|}
\hline No & $\begin{array}{l}\text { Density (kg/ } \\
\left.\mathrm{m}^{3}\right)\end{array}$ & $P_{\max }(\mathrm{kN})$ & $\delta_{\max }(\mathrm{mm})$ & $E_{\mathrm{m}}\left(\mathrm{kN} / \mathrm{mm}^{2}\right)$ & $\sigma_{\mathrm{b}}\left(\mathrm{N} / \mathrm{mm}^{2}\right)$ & $\begin{array}{l}\text { Time to failure } \\
\text { (min) }\end{array}$ & MC (\%) \\
\hline $1-C$ & 518 & 69.73 & 55.98 & 8.50 & 22.8 & 5.4 & 9.6 \\
\hline $2-C$ & 513 & 81.66 & 63.74 & 8.43 & 26.7 & 5.9 & 9.3 \\
\hline $3-C$ & 530 & 70.08 & 56.81 & 8.56 & 22.9 & 5.4 & 9.0 \\
\hline $4-C$ & 520 & 73.45 & 53.82 & 9.28 & 24.0 & 5.2 & 9.3 \\
\hline $5-C$ & 513 & 79.42 & 66.83 & 8.33 & 26.0 & 6.0 & 9.0 \\
\hline $6-C$ & 515 & 68.12 & 53.99 & 8.69 & 22.3 & 5.2 & 9.3 \\
\hline $7-C$ & 504 & 73.88 & 57.61 & 8.39 & 24.2 & 6.6 & 8.9 \\
\hline $8-C$ & 514 & 83.37 & 70.11 & 8.36 & 27.3 & 6.5 & 9.7 \\
\hline $9-C$ & 512 & 66.55 & 61.11 & 7.99 & 21.7 & 5.6 & 8.9 \\
\hline $10-C$ & 515 & 78.50 & 65.33 & 8.55 & 25.7 & 6.1 & 9.0 \\
\hline $11-C$ & 518 & 95.36 & 71.26 & 8.86 & 31.3 & 6.5 & 8.9 \\
\hline Mean & 516 & 76.37 & 61.51 & 8.54 & 25.0 & 5.9 & 9.1 \\
\hline SD & 6 & 8.45 & 6.33 & 0.33 & 2.8 & 0.5 & 0.3 \\
\hline
\end{tabular}

$P_{\max }$ is the maximum load, $\delta_{\max }$ is the displacement at $P_{\max } E_{\mathrm{m}}$ is the bending modulus of elasticity (Eq. 1), $\sigma_{\mathrm{b}}$ is the bending strength (Eq. 2), MC is moisture content, and $\mathrm{SD}$ is the standard deviation 


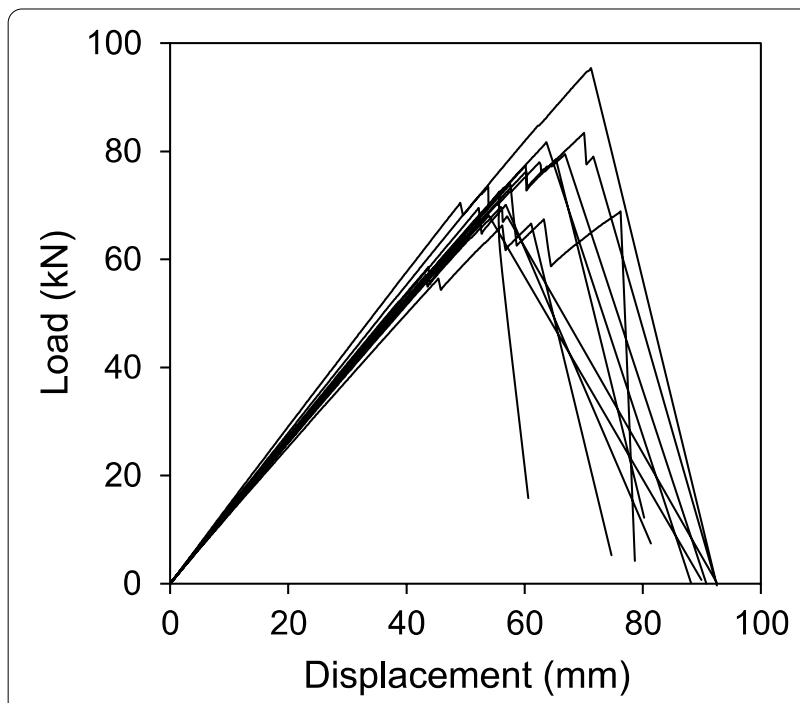

Fig. 4 Load-displacement curves of the short-term loading tests

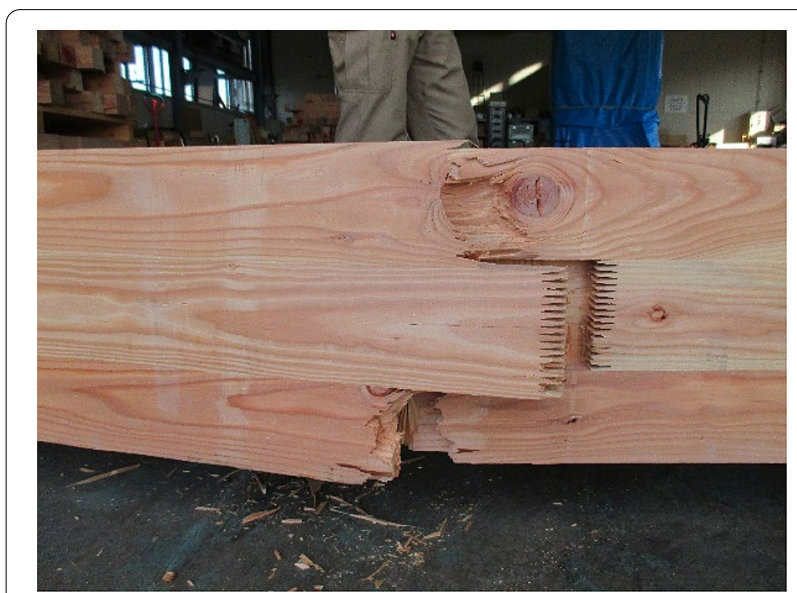

Fig. 5 Failure of a short-term loading test specimen

surface (Fig. 5). The finger joint failure occurred in the wood portion rather than on the adhesive layer. All specimens reached failure after $5-7 \mathrm{~min}$.

\section{Creep tests}

According to the result of the short-term loading test, the constant load used for the creep tests was $28.26 \mathrm{kN}$. Curve fitting to the experimental data of creep deflection was conducted on the basis of a phenomenological model as follows:

$$
\delta_{t}=\delta_{0}+m t^{n}
$$

where $t$ is time, $\delta_{t}$ is the total deflection at time $t, \delta_{0}$ is the initial deflection that includes elastic and plastic deflection, and $n$ and $m$ are constants.
This model is called the power law [4] and has been used in many studies $[5,6]$. The constants $m$ and $n$ were obtained by fitting Eq. (4) to all experimental data using the "nls" function, which is a non-linear least squares method, in the statistics software R version 4.1.0 [17].

Figure 6 shows the relationship between the test period and relative creep $\left(\delta_{t} / \delta_{0}\right)$. The solid line represents the experimental values, and the broken lines correspond to the estimated values obtained by curve fitting. The estimated values almost agree with the experimental values. Table 2 shows the results of the creep tests, including the estimated relative creep after 50 years $\left(\delta_{50 \mathrm{y}} / \delta_{0}\right)$ as an index of long-term creep. It has been reported that additional deformation caused by creep may approximately equal the initial deformation in wood members [13]. Earlier studies on CLT concluded that creep performance was almost equivalent to that of solid lumber and wood-based materials in both a constant environment [11] and a variable environment [12]. All values of $\delta_{50 \mathrm{y}} / \delta_{0}$ were lower than 2.0 in this study, which agrees with the conventional values of wood and earlier studies on CLT. Therefore, seven-layer CLT made from Japanese larch shows satisfactory resistance to creep as a building material; however, this result was derived from the test conducted under constant environmental conditions. Creep deflection accelerates with a moisture content change, which is known as mechano-sorptive creep. Therefore, the result of this study is limited in constant environmental conditions, and additional creep tests might be required under variable environmental conditions.

\section{Creep rupture tests Duration of load}

Table 3 shows the results of the creep rupture tests. Specimens with brank data (4-90 and 7-90) experienced failure before the completion of loading. Most specimens were broken at a finger joint or knot in the tensile surface, which was the same as the short-term loading test. Figure 7 shows the relationship between the duration of load and the loading level. Specimens with failure at less than $1 \mathrm{~min}$ after loading are not shown in Fig. 7. The solid line in Fig. 7 represents an empirical hyperbolic curve based on clear and small specimens [14], which is called the "Madison Curve" and expressed as follows:

$$
y=108.4 x^{0.04635}+18.3
$$

where $y$ is loading level and $x$ is time in seconds.

Many specimens had creep rupture earlier than the Madison curve. Especially, all specimens loaded with $70 \%$ and $60 \%$ loading levels had a shorter duration of load. It is generally assumed that the strength of wood members for a long-term period, which is 10 years or more, is approximately $60 \%$ of that for a short-term period [13]. In 


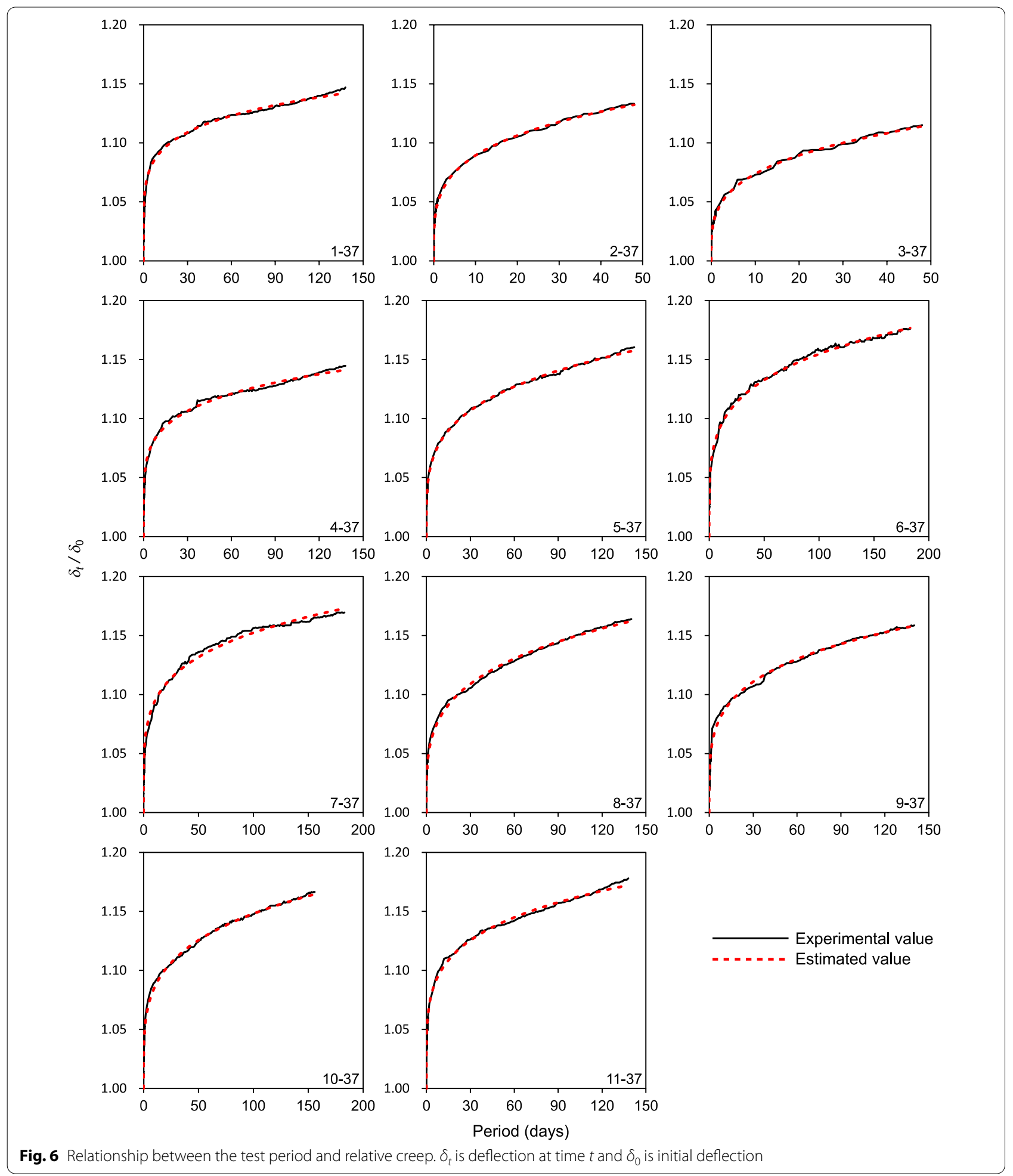

addition, an earlier study concluded that CLT made from Japanese cedar had a duration of load almost equivalent to that for solid lumber [11]. No specimen had a duration of load longer than 1 year, even at a $60 \%$ loading level, in this study. It meant seven-layer CLT made from Japanese larch had a duration of load capacity lower than that of solid lumber and CLT made from Japanese cedar. 
Table 2 Results of the creep tests

\begin{tabular}{|c|c|c|c|c|c|c|}
\hline \multirow[t]{2}{*}{ No } & \multirow[t]{2}{*}{ Density $\left(\mathbf{k g} / \mathrm{m}^{3}\right)$} & \multirow[t]{2}{*}{ Test period (days) } & \multirow[t]{2}{*}{$\delta_{0}(\mathrm{~mm})$} & \multicolumn{3}{|c|}{ Estimated value } \\
\hline & & & & $m$ & $n$ & $\delta_{50 \mathrm{y}} / \delta_{0}$ \\
\hline $1-37$ & 511 & 138 & 21.04 & 0.357 & 0.174 & 1.33 \\
\hline $2-37$ & 506 & 48 & 22.72 & 0.184 & 0.251 & 1.59 \\
\hline $3-37$ & 525 & 48 & 19.50 & 0.102 & 0.277 & 1.59 \\
\hline $4-37$ & 517 & 138 & 20.67 & 0.301 & 0.186 & 1.35 \\
\hline $5-37$ & 507 & 142 & 21.37 & 0.158 & 0.250 & 1.53 \\
\hline $6-37$ & 513 & 183 & 21.14 & 0.238 & 0.221 & 1.49 \\
\hline $7-37$ & 504 & 183 & 21.81 & 0.272 & 0.211 & 1.46 \\
\hline $8-37$ & 513 & 140 & 20.67 & 0.143 & 0.259 & 1.57 \\
\hline $9-37$ & 517 & 140 & 20.93 & 0.196 & 0.231 & 1.49 \\
\hline $10-37$ & 512 & 156 & 21.56 & 0.189 & 0.238 & 1.51 \\
\hline $11-37$ & 507 & 138 & 21.55 & 0.294 & 0.208 & 1.48 \\
\hline Mean & 512 & & 21.18 & 0.221 & 0.228 & 1.49 \\
\hline SD & 6 & & 0.81 & 0.078 & 0.031 & 0.09 \\
\hline
\end{tabular}

$\delta_{0}$ is initial deflection, $\delta_{50 y}$ is predicted deflection after 50 years, $m$ and $n$ are constants (see Eq. 4), and SD is the standard deviation

\section{Survival analysis}

Survival analysis is a collection of statistical procedures for data analysis for which the outcome variable of interest is time until an event occurs [18]. It is a popular data analysis approach in epidemiologic and reliability engineering. Because duration of load is time until a failure event occurs, survival analysis was conducted on duration of load in this study. Figure 8 shows survival curves derived from survival analysis using the Kaplan-Meier method, which is non-parametric method, and parametric model of the Weibull distribution. This analysis was implemented by the statistics software $R$ version 4.1.0 [17]. One second was applied to the duration of load of specimens with failure before the completion of loading (4-90 and 7-90) for this analysis. The solid and broken lines represent survival curves obtained by the Kaplan-Meier method and the Weibull model, respectively. Kaplan-Meier survival curves in Fig. 8 represented experimental curves because data were not censored in this study. The survival curves derived on the basis of the Weibull distribution almost agreed with those of the Kaplan-Meier method. The probability density function of survival time based on the Weibull distribution used in this analysis is as follows:

$$
f\left(t_{\mathrm{s}}\right)=\lambda \gamma t_{\mathrm{s}}^{\gamma-1} e^{-\lambda t_{\mathrm{s}}^{\gamma}}
$$

where $t_{\mathrm{s}}$ is survival time in hours, $\lambda$ is the scale factor, and $\gamma$ is the shape factor.

The survival function $S\left(t_{\mathrm{s}}\right)$ and hazard function $h\left(t_{\mathrm{s}}\right)$ are as follows:

$$
S\left(t_{\mathrm{s}}\right)=e^{-\lambda t_{\mathrm{s}}^{\gamma}}
$$

$$
h\left(t_{\mathrm{s}}\right)=\lambda \gamma t_{\mathrm{s}}^{\gamma-1}
$$

The value of shape factor $\gamma$ determines the characteristic of instantaneous failure rate, which is represented as the hazard function Eq. (8). When $\gamma$ is less than 1.0, the failure rate is high at the early period and decreases with time. This type of failure was observed in the specimen loaded with $90 \%(\gamma=0.306), 80 \%(\gamma=0.614)$, and $70 \%$ $(\gamma=0.769)$ loading levels in this study. When $\gamma$ is 1.0 , the failure rate remains constant. When $\gamma$ is greater than 1.0 and less than 2.0, the failure rate is low at the beginning and gradually increases, reducing the rate of increase. When $\gamma$ is 2.0, the failure rate increases with time linearly. When $\gamma$ is greater than 2.0, the failure rate increases with time, increasing the rate of increase. The specimen loaded with a $60 \%$ loading level $(\gamma=2.194)$ showed this type of failure. As a result, an initial failure was observed in specimens loaded with $90 \%, 80 \%$, and $70 \%$ loading levels. The occurrence of initial failure is undesirable for safety in timber use. Thus, a 70\% loading level or more should be avoided in CLT members made from Japanese larch. In addition, the creep rupture behavior changed between 70 and $60 \%$ loading levels. A long-term loading test with multi-levels less than $70 \%$ loading level and observation of survival curves would be required to determine allowable loading levels in long-term use of CLT made from Japanese larch.

\section{Progress of deflection until failure}

Figure 9 shows the deflection at the span center $(\delta)$ until failure. The creep behavior under continuous stress has three phases of deflection increase [19]. They are rapid increase in the early period (primary creep), relatively 
Table 3 Results of the creep rupture tests

\begin{tabular}{|c|c|c|c|c|c|}
\hline $\begin{array}{l}\text { Loading } \\
\text { level (\%) }\end{array}$ & No & $\begin{array}{l}\text { Density } \\
\left(\mathrm{kg} / \mathrm{m}^{3}\right)\end{array}$ & $\begin{array}{l}\text { Duration of } \\
\text { load (min) }\end{array}$ & $\delta_{\text {final }}(\mathrm{mm})$ & MC (\%) \\
\hline \multirow[t]{11}{*}{60} & $1-60$ & 509 & 182,344 & 51.81 & 9.5 \\
\hline & $2-60$ & 502 & 427,229 & 60.98 & 10.2 \\
\hline & $3-60$ & 509 & 225,096 & 47.17 & 9.9 \\
\hline & $4-60$ & 518 & 55,625 & 46.79 & 9.4 \\
\hline & $5-60$ & 518 & 91,382 & 51.83 & 9.3 \\
\hline & $6-60$ & 514 & 210,513 & 52.62 & 9.8 \\
\hline & $7-60$ & 513 & 161,047 & 61.58 & 10.1 \\
\hline & $8-60$ & 523 & 335,472 & 55.11 & 10.0 \\
\hline & $9-60$ & 512 & 361,090 & 65.53 & 10.2 \\
\hline & $10-60$ & 505 & 223,180 & 48.38 & 10.2 \\
\hline & $11-60$ & 502 & 167,463 & 44.57 & 9.8 \\
\hline \multirow[t]{11}{*}{70} & $1-70$ & 504 & 59,856 & 55.36 & 9.7 \\
\hline & $2-70$ & 497 & 12,053 & 60.84 & 10.1 \\
\hline & $3-70$ & 516 & 10,495 & 54.93 & 9.9 \\
\hline & $4-70$ & 515 & 42,891 & 47.00 & 10.3 \\
\hline & $5-70$ & 523 & 88 & 42.33 & 9.7 \\
\hline & $6-70$ & 516 & 21,984 & 47.05 & 9.9 \\
\hline & $7-70$ & 515 & 616 & 43.35 & 10.1 \\
\hline & $8-70$ & 512 & 23,928 & 53.75 & 9.9 \\
\hline & $9-70$ & 508 & 56,128 & 55.42 & 10.7 \\
\hline & $10-70$ & 512 & 1858 & 44.46 & 9.6 \\
\hline & $11-70$ & 503 & 20,232 & 47.58 & 9.8 \\
\hline \multirow[t]{11}{*}{80} & $1-80$ & 511 & 1576 & 51.63 & 9.9 \\
\hline & $2-80$ & 504 & 520 & 47.98 & 10.0 \\
\hline & $3-80$ & 522 & 75 & 52.41 & 10.2 \\
\hline & $4-80$ & 515 & 84 & 46.36 & 9.9 \\
\hline & $5-80$ & 515 & 170 & 52.38 & 10.0 \\
\hline & $6-80$ & 516 & 59 & 54.50 & 10.0 \\
\hline & $7-80$ & 507 & 3238 & 50.95 & 9.8 \\
\hline & $8-80$ & 525 & 2158 & 67.02 & 10.2 \\
\hline & $9-80$ & 513 & 393 & 54.30 & 10.6 \\
\hline & $10-80$ & 500 & 10,323 & 53.07 & 10.5 \\
\hline & $11-80$ & 518 & 182 & 63.44 & 9.6 \\
\hline \multirow[t]{11}{*}{90} & $1-90$ & 523 & 648 & 54.17 & 10.0 \\
\hline & 2-90 & 505 & 118 & 60.96 & 10.1 \\
\hline & $3-90$ & 522 & 3 & 52.29 & 10.5 \\
\hline & 4-90 & 515 & - & 50.24 & 9.8 \\
\hline & $5-90$ & 511 & 806 & 56.86 & 10.0 \\
\hline & 6-90 & 510 & 3929 & 60.53 & 10.3 \\
\hline & 7-90 & 503 & - & 55.48 & 10.2 \\
\hline & 8-90 & 512 & 0 & 55.02 & 9.9 \\
\hline & 9-90 & 524 & 19 & 57.21 & 10.1 \\
\hline & $10-90$ & 515 & 90 & 58.52 & 10.0 \\
\hline & $11-90$ & 520 & 142 & 50.27 & 9.7 \\
\hline
\end{tabular}

$\delta_{\text {final }}$ is the final recorded deflection before failure and $M C$ is moisture content. Specimens with brank data had failure before the completion of loading

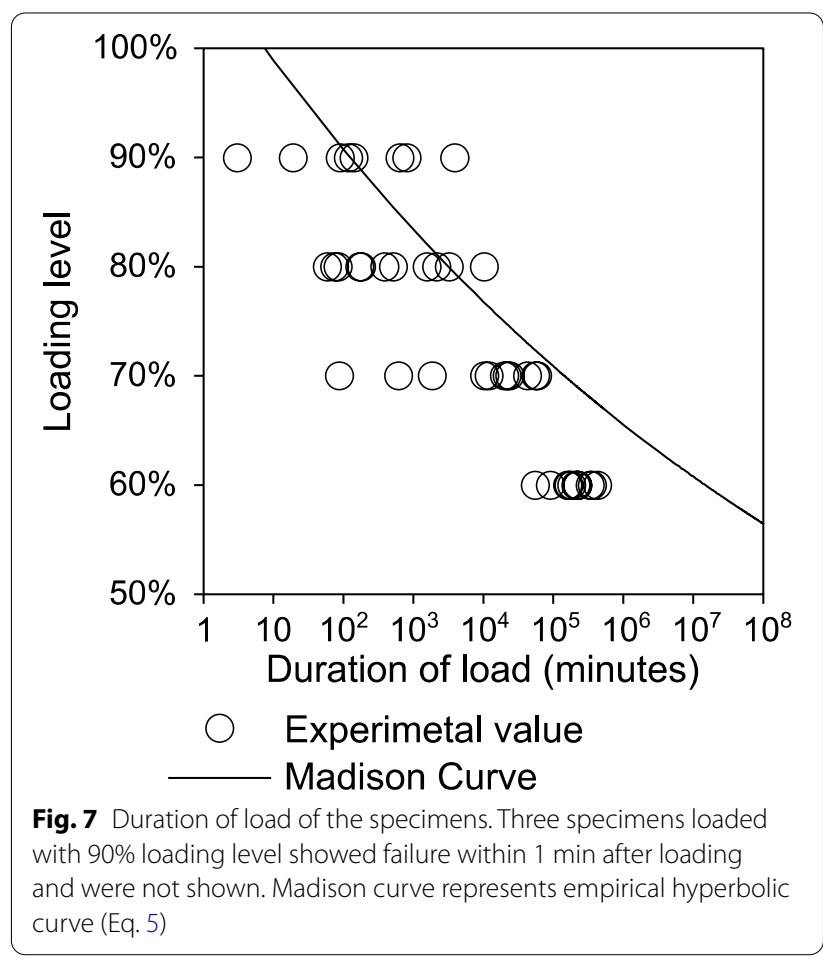

slow increase after primary creep (secondary creep), and rapid increase leading to a failure (tertiary creep). The tertiary creep of most of the specimens showed an extreme change in the increase rate of deflection after secondary creep in this study. Moreover, some specimens showed almost no tertiary creep. Several specimens showed a step-wise increase in deflection. It possibly meant that one-by-one failure in laminae at the tensile surface occurred. Specimens in this study had three laminae in width (Figs. 1, 5). Although one lamina broke, the other laminae might carry a continuous load. Specimens that showed almost no tertiary creep might have simultaneous failure in all laminae in the tensile surface. Then, the width of a specimen, which is the number of laminae in width on the tensile surface, could affect creep rupture behavior.

In addition, most creep rupture specimens showed lower last recorded deflection before failure than displacement at a maximum load in the short-term loading test that was $61.51 \mathrm{~mm}$ in mean (Table 1). The deformation at failure is approximately the same for a long-term and short-term loading test in the case of solid wood [13]. Then, CLT could have a different 


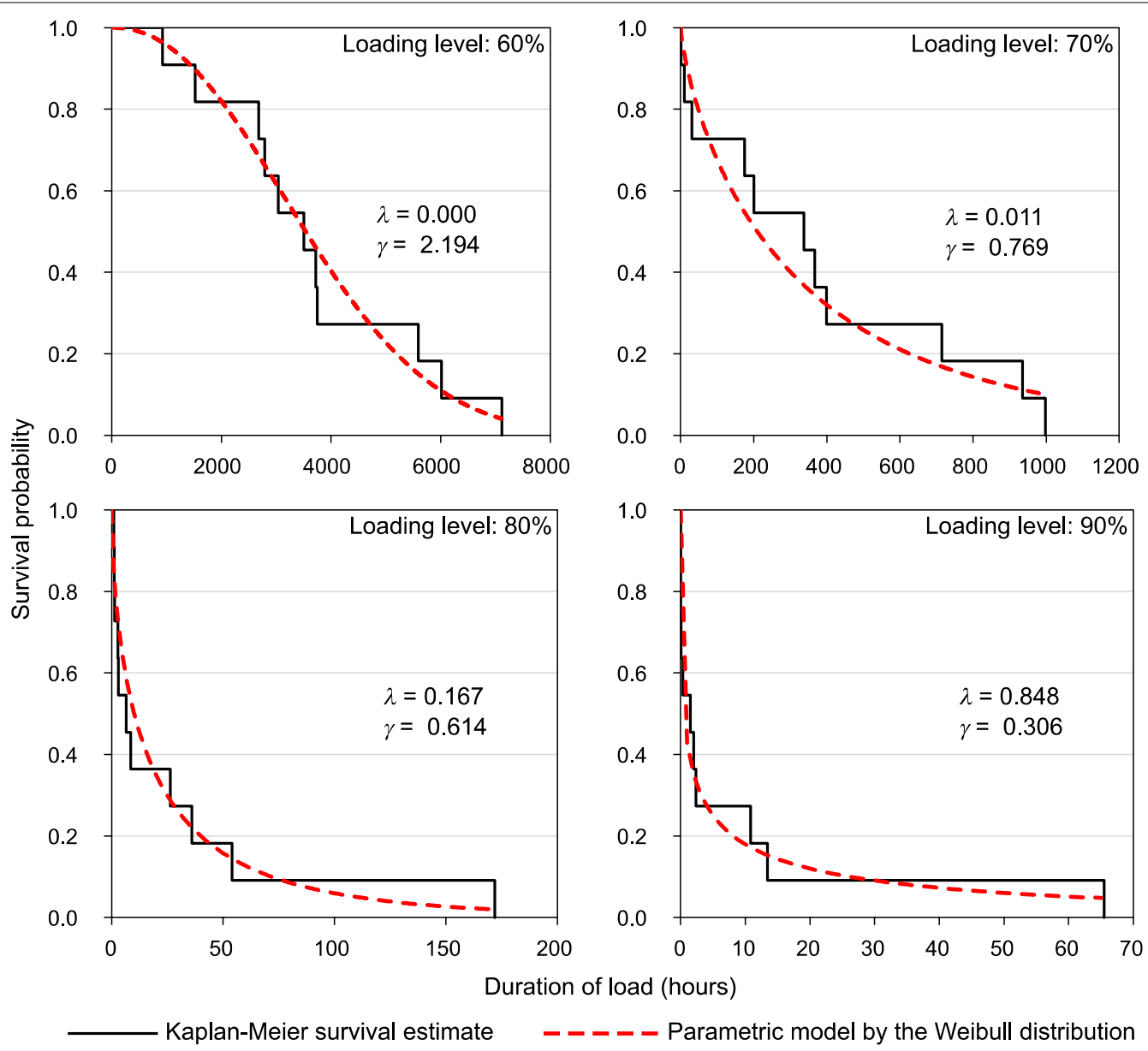

Fig. 8 Results of the survival analysis. $\lambda$ and $\gamma$ are scale and shape factors of the Weibull distribution, respectively (see Eq. 6)

manner of creep rupture from other wooden materials. Differences between CLT and other wooden materials are the existence of finger joints and transverse layers. They possibly influence long-term failure behavior.

\section{Conclusions}

We conducted long-term out-of-plane bending tests in a constant environment, investigated creep performance and the duration of load, and experimentally analyzed creep rupture behavior on seven-layer CLT made from Japanese larch. The results of the test were as follows:

1. Estimated relative creep after 50 years was 1.49 in mean. It was the lower value of relative creep compared to the conventional value of wood. Seven-layer CLT made from Japanese larch shows a satisfactory resistance to creep as a building material.
2. The duration of load of most of the specimens was shorter than the value for solid lumber. Especially, specimens loaded with $70 \%$ and $60 \%$ loading levels had a shorter duration of load than that.

3. Initial failure was observed in specimens loaded with $90 \%, 80 \%$, and $70 \%$ loading levels in this study. A $70 \%$ loading level or more should be avoided in CLT members made from Japanese larch.

4. Most specimens showed extreme conversion from secondary creep to tertiary creep. Several specimens showed almost no tertiary creep before failure. Creep rupture of most of the specimens occurred at less deflection than displacement at failure in the shortterm loading test. The effects of finger joints, transverse layers, and width of a specimen on creep rupture behavior should be estimated in future work. 

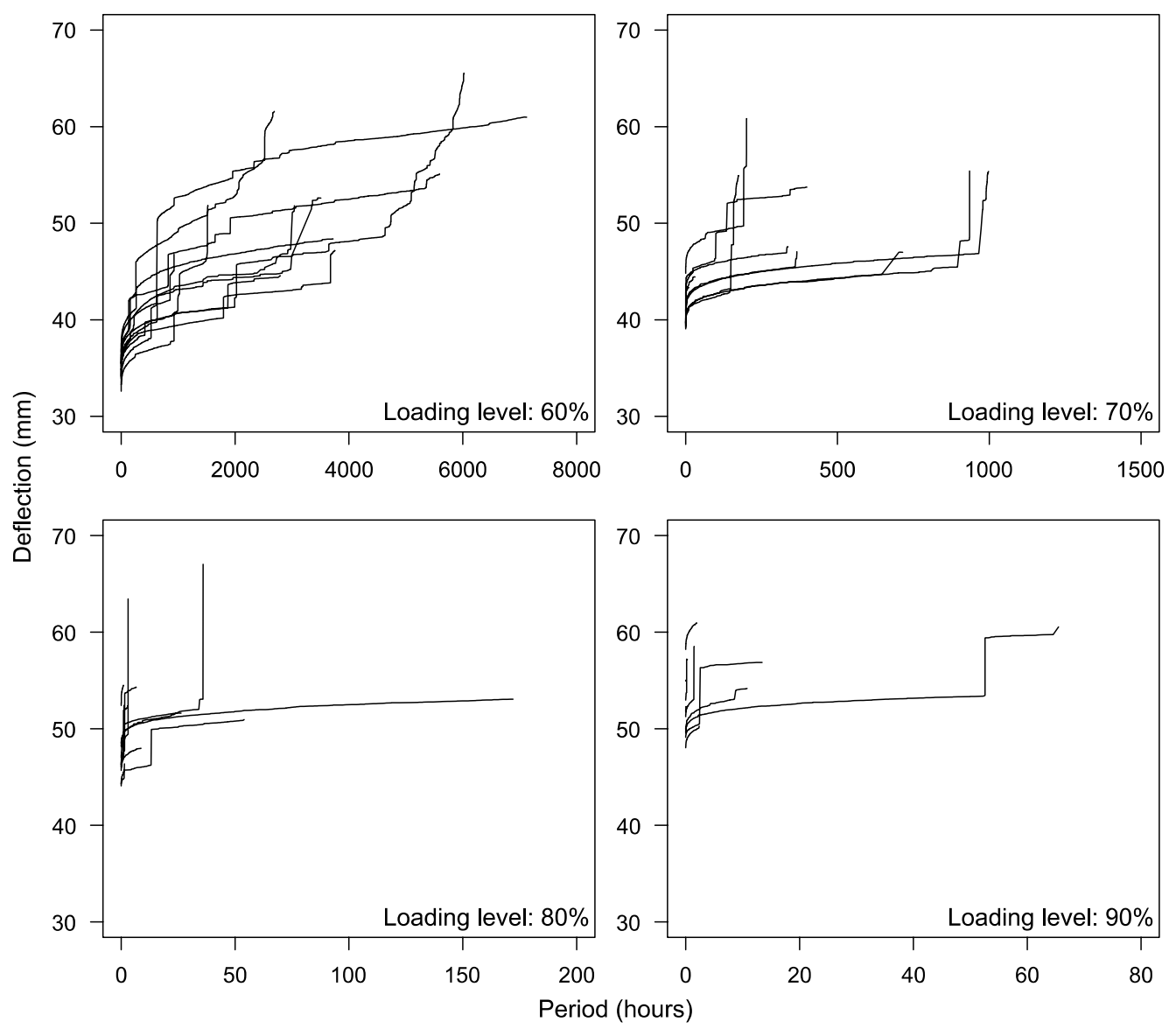

Fig. 9 Deflection at span center of specimens with time

\section{Abbreviations}

$P$ : Load; $\delta$ : Displacement; $E_{\mathrm{m}}$ : Bending modulus of elasticity; $\sigma_{\mathrm{b}}$ : Bending strength; $P_{\max }$ : Maximum load; $\triangle P$ : Load increase in an elastic range; $\Delta \delta$ : Displacement increase in an elastic range; $L$ : Length of the support span; $b$ : Specimen width; $h$ : Specimen thickness; $\mathrm{RH}$ : The relative humidity; $\delta_{\max }$ : Displacement at $P_{\text {max }}: M C$ : Moisture content; SD: The standard deviation; $t$ :Time; $\delta_{t}$ : Total deflection at time $t ; \delta_{0}$ : Initial deflection; $n$ : Constant; $m$ : Constant; $\delta_{50 y}$ : Estimated deflection after 50 years; $\delta_{\text {final: }}$ Final recorded deflection before failure; $y$ : Loading level; $x$ : Time in seconds; $f\left(t_{\mathrm{s}}\right)$ : The probability density function; $t_{s}$ : Survival time in hours; $\lambda$ : The scale factor; $\gamma$ : The shape factor; $S\left(t_{s}\right)$ : The survival function; $h\left(t_{5}\right)$ : The hazard function.

\section{Acknowledgements}

The authors appreciate Okhotsk Woodpia, Butsurin Co. Ltd, and Meiken Lamwood Corp. for providing the specimens.

Some part of this study were presented at the annual meeting of the Architectural Institute of Japan, Hiroshima, September 2017 and World Conference on Timber Engineering, Seoul, August 2018.

\section{Authors' contributions}

$\mathrm{RT}, \mathrm{YO}$, and KM planned the research. All authors contributed to preparing the specimens, conducting the tests, and analyzing the data. RT wrote the manuscript. All authors read and approved the final manuscript.

\section{Funding}

This study was conducted under the subsidiary project of the Forest Agency, Japan in 2017

\section{Availability of data and materials}

The datasets used and analyzed during the current study are available from the corresponding author on reasonable request.

\section{Declarations}

Competing interests

The authors declare that they have no competing interests.

Received: 25 September 2021 Accepted: 12 November 2021

Published online: 25 November 2021

\section{References}

1. Brandner R, Flatscher G, Ringhofer A, Schickhofer G, Thiel A (2016) Cross laminated timber (CLT): overview and development. Eur J Wood Prod 74:331-351

2. FPInnovations (2011) CLT handbook: cross-laminated timber Canadian edition. FPInnovations, Quebec 
3. Sikora K, Mcpolin D, Harte A (2016) Effects of the thickness of cross-laminated timber (CLT) panels made from Irish Sitka spruce on mechanical performance in bending and shear. Constr Build Mater 116:141-150

4. Holzer S, Loferski J, Dillard D (1989) A review of creep in wood: concepts relevant to develop long-term behavior predictions for wood structures. Wood Fiber Sci 21:376-392

5. Aratake S, Arima T (1995) Creep of sugi sawn lumber in process of humidity changes. Mokuzai Gakkaishi 41:359-366 (in Japanese)

6. Ohashi Y, Matsumoto K, Sato T, Hirai T (2008) Mechanical properties of wooden I-beams with plantation timber materials in Hokkaido II: long term bending creep property. Mokuzai Gakkaishi 54:174-182 (in Japanese)

7. Aratake S, Morita H, Arima T (2011) Bending creep of glued laminated timber (glulam) using sugi (Cryptomeria japonica) laminae with extremely low Young's modulus for the inner layers. J Wood Sci 57:267-275

8. Gerhards C (2000) Bending creep and load duration of Douglas-fir 2 by $4 \mathrm{~s}$ under constant load for up to 12-plus years. Wood Fiber Sci 32:489-501

9. Park H, Fushitani M, Sato K, Kubo T, Byeon H (2006) Bending creep performances of three-ply cross-laminated woods made with five species. J Wood Sci 52:220-229

10. Jöbst R, Schickhofer G (2007) Comparative examination of creep of GLTand CLT-slabs in bending. In: CIB-W18, Bled, Slovenia, August 2007

11. Nakajima S, Miyatake A, Shibusawa T, Araki Y, Yamaguchi N, Haramiishi T, Ando N, Yasumura M (2014) Creep and duration of load characteristics of cross laminated timber. In: World conference on timber engineering, Quebec City, Canada, August 2014
12. Pirvu C, Karacabeyli E (2014) Time-dependent behaviour of CLT. In: World conference on timber engineering, Quebec City, Canada, August 2014

13. USDA Forest Products Laboratory (2010) Mechanical properties of wood. In: Wood handbook: wood as an engineering material, Madison, pp 39-40

14. Wood L (1951) Relation of strength of wood to duration of load. USDA Forest Service Forest Products Laboratory Report No R1916

15. Schniewind A, Lyon D (1973) Further experiments on creep-rupture life under cyclic environmental conditions. Wood Fiber Sci 4:334-341

16. The Ministry of Agriculture, Forestry and Fisheries (2019) Japanese Agricultural Standard for Cross Laminated Timber (JAS3079). The Ministry of Agriculture, Forestry and Fisheries, Tokyo (in Japanese)

17. R Core Team (2021) R: a language and environment for statistical computing. R Foundation for Statistical Computing, Vienna, Austria, https:// www.R-project.org/. Accessed 24 Sept 2021

18. Kleinbaum D, Klein M (2012) Introduction to survival analysis. Survival analysis. Springer, New York, pp 1-54

19. Reichel S, Kaliske M (2015) Hygro-mechanically coupled modelling of creep in wooden structures Part I: mechanics. Int J Solids Struct 77:28-44

\section{Publisher's Note}

Springer Nature remains neutral with regard to jurisdictional claims in published maps and institutional affiliations.

\section{Submit your manuscript to a SpringerOpen ${ }^{\circ}$ journal and benefit from:}

- Convenient online submission

$\checkmark$ Rigorous peer review

- Open access: articles freely available online

- High visibility within the field

- Retaining the copyright to your article

Submit your next manuscript at $\boldsymbol{\nabla}$ springeropen.com 